\title{
A multi-scale ecohydrological model for assessing floodplain wetland response to altered flow regimes
}

\author{
$\underline{\text { M.R. Hipsey }}^{\text {a,b }}$, R. Vogwill ${ }^{\text {a,c }}$, D. Farmer ${ }^{c}$ and B.D. Busch ${ }^{\text {b,a }}$ \\ ${ }^{a}$ School of Earth and Environment, The University of Western Australia, \\ 35 Stirling Highway, Crawley WA 6009, Australia. \\ Email: matt.hipsey@uwa.edu.au \\ ${ }^{b}$ Centre for Ecohydrology, School of Environment Systems Engineering, The University of Western \\ Australia, 35 Stirling Hwy, Crawley WA 6009, Australia \\ ${ }^{c}$ Department of Environment and Conservation, Government of Western Australia, 17 Dick Perry Ave, \\ Kensington WA 6151, Australia.
}

\begin{abstract}
The valley floors of semi-arid Australian catchments are generally characterized by floodplain wetland systems with high biodiversity value, however they are threatened by degradation processes brought about by land-use changes. Altered hydrology from large-scale native vegetation clearing and shifting runoff and streamflow regimes have significantly altered floodplain hydrological processes, and often natural resource management decisions within the wider catchment are implemented with limited consideration of lower landscape environments. Our aim has been to develop a spatially distributed ecohydrological model that will allow us to assess the affects of hydrological change and consider optimal management strategies that integrate vegetative and engineering approaches to protect biodiversity assets in the lower landscape. A significant barrier to developing such a tool was addressing the range of spatial and temporal scales that must be considered and the paucity of data available to implement suitable models. To overcome these issues this study adopts a high-resolution model for the floodplain and associated wetlands to simulate in detail the flows, patterns of inundation and riparian hydrology of the valley floor, and this is nested within a coarser scale catchment model able to resolve the essential hydrological dynamics of the surrounding landscape. The model system was applied to the Lake Bryde Natural Diversity Recovery Catchment, located in south-west Western Australia, and model predictions of flow and floodplain inundation were validated against limited data from a flood event that occurred in January 2006. The model system was able to demonstrate the effects of hydraulic constrictions (eg. roads impediments and culvert impacts), likely pre- and post-European behaviours, re-vegetation effects, and altered rainfall patterns on inundation dynamics upon the valley floor conservation areas.
\end{abstract}

Keywords: semi-arid climate, vegetation response, hydrology model, floodplain inundation, salinity, LASCAM, ELCOM, threatened ecological community 


\section{INTRODUCTION}

The valley floors of semi-arid Australian catchments are generally characterized by broad, flat riparian landscapes with discontinuous and braided channels, networks of floodplain wetlands and playa lake systems. They have an intrinsically high natural diversity that has evolved closely with local hydrological regimes. However, in modern landscapes the remnant systems represent declining pockets of high biodiversity value that are increasingly threatened by degradation brought about by an increase in the frequency of short-intense events that are enhanced by land-clearing and surface drainage works. Examples of management issues relevant to the biodiversity associated with remnant valley floor systems include:

- Increasing salinity due to rising water tables (eg. south-west Western Australia), or alternatively from low flows during drought or from excessive water harvesting (eg. Murray-Darling Basin), leading to increasing stress on vegetation communities;

- Excessive waterlogging and prolonged inundation promoted by degraded drainage networks and increased shedding of water from cleared lands limits plant growth and salt accumulation;

- Exposure of acid sulfate soils and subsequent risks associated temporary or permanent acidification;

- Drought and water quality impacts on water-dependent aquatic fauna;

- Altered nutrient and resource delivery impacts on food web function.

Natural resource management decisions within the wider catchment are often implemented at local scales without full consideration of these important downstream environments. The challenge is to develop a sound numerical tool for assessing the key ecohydrological dynamics of these important environmental systems that can be used within a suitable management framework to optimise the mix of perennial re-vegetation and engineering initiatives to protect biodiversity assets threatened by altered hydrological regimes brought about by land-clearing, over-allocation of water, or climate variability. A significant barrier to developing such a tool is the range of spatial and temporal scales that must be considered and the lack of data required to develop suitable models. For example, degradation of flat valley floor areas may result from relatively finescale hydraulic controls caused by poorly functioning road culvert-floodway systems or paddock-scale drainage works implemented to manage excess water, flood events or salinity. Concurrently, regional changes in rainfall quantities and patterns over several decades are also having a large impact on groundwater levels and the periodicity and extent of valley floor flooding.

The current tools available for understanding these dynamics are not well suited to explore these questions within the Australian context. Routinely used hydrological models are suited to prediction of rainfall-runoff processes on the upper slopes, but tend to lack necessary sophistication in resolving hydrological dynamics of the complex floodplain-wetland system where the important biodiversity is centred. Surface water flooding models are at the opposite end of the spectrum and are good for resolving flood evolution and water spreading, but lack any real integration with broader landscape processes. Few options exist that have attempted to cross this gap by linking catchment hydrology and surface water floodplain dynamics. Combined approaches incorporating both hydraulic behaviour interactively with key plant, soil, groundwater and hydrochemistry processes demand high-resolution computational discretisation across the landscape and are notoriously data and parameter intensive, which is a particular problem in remote and data poor catchments. Costelloe et al. (2003; 2006) demonstrated the use of a novel grid-based conceptual water balance model as a useful approach to help understand flood dynamics in an arid river system, which was run at a daily time-step to avoid the high computational loads of a fully distributed modelling approach.

Within this study we wish to understand the dynamics of high value biodiversity assets within the wider catchment context. Thus we desire detailed process representation at the immediate valley scale with the incorporation of contributing behaviours from hillsope areas of the catchment at appropriate complexity, but without the computationally excessive high resolution requirement. Our aim has been to develop a multiscale catchment-floodplain model suited to application in these environments that increases in model resolution and complexity closer to the management area of high interest, thereby focusing our efforts in areas of most importance. This is unlike other integrated model platforms which focus on parameterising and deterministically modelling the whole catchment at high resolution, and attempts to provide a modelling framework that balances simplicity and complexity.

\section{INTEGRATED MULTI-SCALE MODEL APPROACH}

Most arid/semi-arid Australian catchments in low relief landscapes are characterized by a low-lying valley floor with low gradient and poorly defined flow pathways. Commonly used rainfall-runoff and hydraulic routing approaches are inadequate since they are unable to accurately predict movement of water once it exits the "shedding" (ie. slope $>2 \%$ ) regions and enters the flat valley floor. In the low-lying areas the classical 
hillslope hydrology conceptual models break down and hydraulic considerations dominate since it is these processes that govern how the water will move. In particular, local depressions and man-made structures, such as roads and banks, govern flow continuity. Simplified streamflow routing assumptions therefore become inadequate and can not capture the highly braided nature of the flows. More sophisticated hydraulic models could be used, but their treatment of the rainfall-runoff response is too simplistic for the dry, flat landscapes typical in the wheatbelt, and they also do not include recharge/discharge processes and riparian zone dynamics which are of relevance to biodiversity management.

Here we introduce a hybrid model approach that reflects the range of scales and requirements that are required to assess floodplain ecohydrological dynamics. This includes the simulation of a) the wider catchment hydrology dynamics using a conceptual hillslope water balance model whose predictions are used as input to the valley floor regions, b) the local ecohydrological dynamics of the floodplain itself, and c) potentially the simulation of specific ecological and/or biogeochemical dynamics within the wetland or floodplain areas in response to hydrological drivers (not discussed further here). The catchment hydrological component adopts a different scale of simulations than the floodplain/wetland model, and is designed to capture the essential hydrological dynamics using a relatively coarse spatial disaggregation. Here we use LASCAM (Viney and Sivapalan, 2000, Sivapalan et al., 2002) however the approach is potentially viable with alternate models. The floodplain model is a high-resolution surface water model (ELCOM), which is linked to a simple cell-based soil hydrological model (based on Farmer et al. 2000; 2003) in each of the dry cells to account for riparian-zone hydrology and vegetation interaction. The combined simulation framework allows us to cover a range of temporal and spatial scales that no single model can adequately answer alone.

In this study, we demonstrate the approach on the Lake Bryde Natural Diversity Recovery Catchment (LBNDRC), located in the wheatbelt of southwest Western Australia. Its high natural diversity is at risk from rising water tables and secondary salinity from inundation, waterlogging and runoff mobilised salt. The aim of management is to slow the rate of decline of biodiversity across substantive remnant valley floor assemblages and to conserve specific high value assets. The mostly uncleared valley floor floodplain comprises the Lake Bryde and Lakeland Nature Reserves. These contain a range of vegetation species and assemblages that include declared rare flora (DRF), and a number of diverse lakes and wetlands - including two with Threatened Ecological Communities (TEC) present. There are also pockets and other wetlands within the system where DRF and TEC have previously been present and have declined.

The large-scale hydrological model was applied to the LBNDRC and includes 72 sub-catchments, of which 16 deliver water to the boundaries of the Nature Reserves, which is the high-resolution valley floor region (Figure 1). Here we report application of the model system over two time-scales: during a large flood event, and over a multi-decadal period to provide initial insight to likely changes in basin hydrological behaviour.

\section{FLOOD HYDROLOGY IN LAKE BRYDE NATURE RESERVE}

The model was applied during a large flood event that occurred in Jan 2006 following more than $140 \mathrm{~mm}$ in 24 hours. The catchment model was run for the preceding 10yrs (1996-2006) and used to generate flows to the floodplain model, which was run for 1 month during Jan 2006. Model scenarios included the actual situation (highlighting likely stress areas), a hypothetical engineered waterway running through the domain (to assess the potential for managing the extent and period of residual ponding and waterlogging pressures), and a predevelopment scenario to ascertain the potential role played by road impediments.

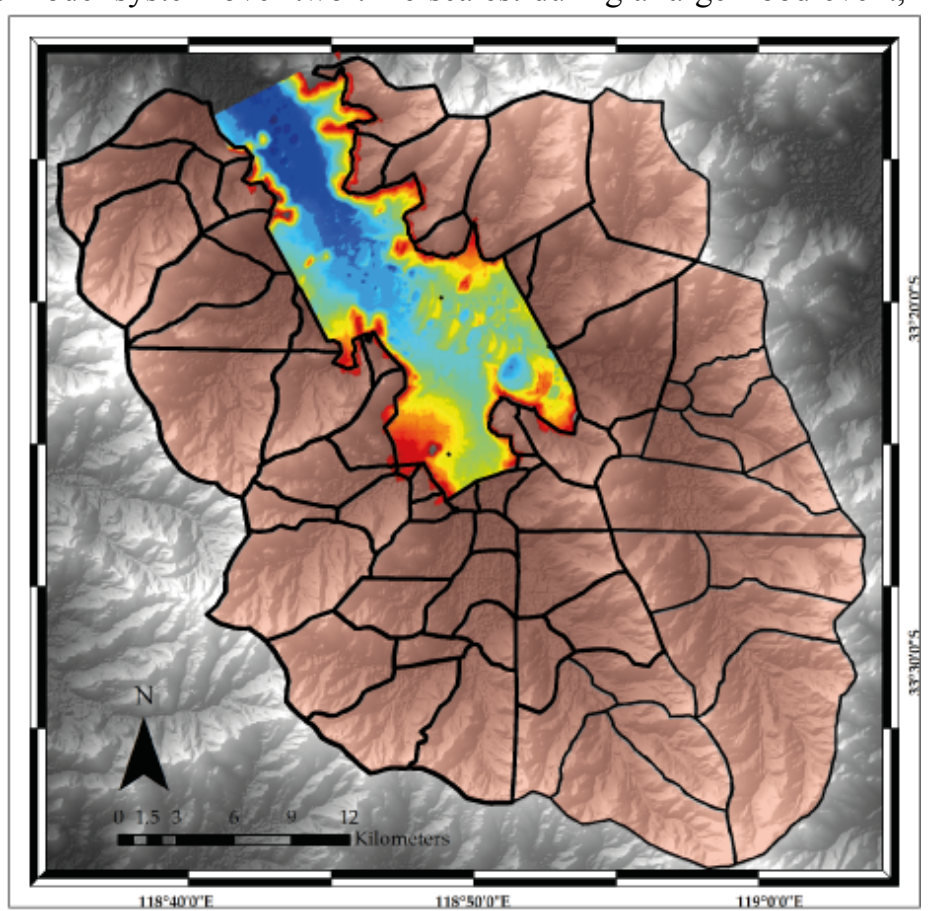

Figure 1. LBNDRC located in southwest WA, showing the coupling of a large-scale catchment model (red lines indicate subcatchment delineation), and a high-resolution floodplain model (colour inset indicates $50 \times 50 \mathrm{~m}$ model grid). 


\subsection{Model Application}

The topographic information for the ELCOM grid was generated from a photogrammetry derived DEM $(15 \mathrm{~m}$ resolution) for the lower valley. The topography was rotated $\left(27^{\circ}\right.$ clockwise $)$ to align with the valley floor elevation gradient, and was re-sampled to a resolution of $50 \mathrm{~m}$. Cells above $310 \mathrm{mAHD}$ were masked out, and assumed to be covered by the surrounding sub-catchments of the hillslope model (Section 4). The model simulations started with a typical dry summer domain prior to the flood, and
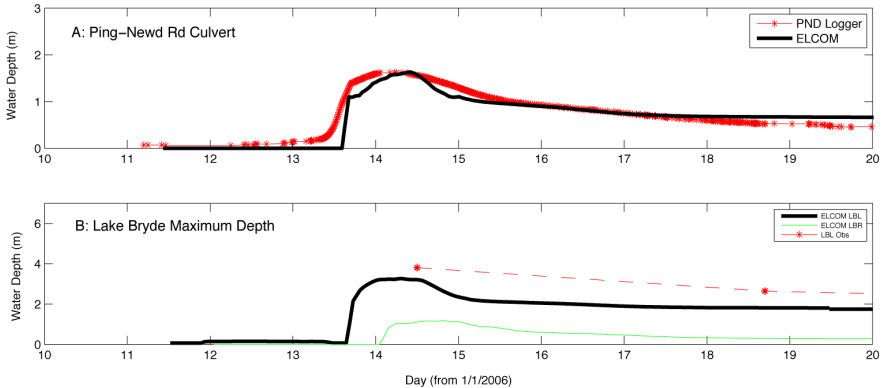

Figure 2. Comparison of flood inundation depths at two key locations in the valley floor (A: Pingrup-Newdegate $\mathrm{Rd}$ culvert/floodway; B: Lake Bryde deep point) between observations and model output. were run with a 30s time-step for the month of Jan 2006.

To explore the effect of the engineered waterway, an alternative grid was configured by imprinting the channel into the domain. The channel depths were notionally set to $0.5 \mathrm{~m}$ depth from the base topography, but due to undulations in the base domain, the channel depths were manually smoothed to ensure a monotonic drop in channel depth across the valley floor domain as in reality.

The model simulates variable roughness effects in the catchment, based on a drag coefficient, $C_{D}$, which applies a bottom drag accounting for the vegetation and the soil condition. The spatial grid for drag representation was developed by converting the remnant vegetation GIS file for the region onto the numerical grid, and assigning a Manning's $n$ of 0.07 for cells with remnant vegetation, and 0.02 for cells that represent agricultural land. These were converted to $C_{D}$ by putting Manning's equation $\left(U=[1 / n] H^{2 / 3} S^{1 / 2}\right)$ into the definition of $C_{D}\left(=\left[u^{*} / U\right]^{2}\right)$, to get: $C_{D}=g n^{2} / H^{1 / 3}$, by assuming that $u^{{ }^{* 2}}=g H S$. For simulations with the engineered waterway, a smooth drag value was used for the channel cells.

Soil-landscape mapping was used to develop soil maps for the numerical domain to drive the soil hydrological model. They are classed as four main types for the valley-floor system, summarised as HydroAeolian (sandy clays over clays), Alluvial Clays (grey depositional clays), Upper Valley Alluvials (grey clays / shallow duplex) and Narrow Valley Floor (sandy duplex). These were mapped onto the floodplain grid and for each sub-type typical soil hydrological and textural parameters were assumed for the soil model.

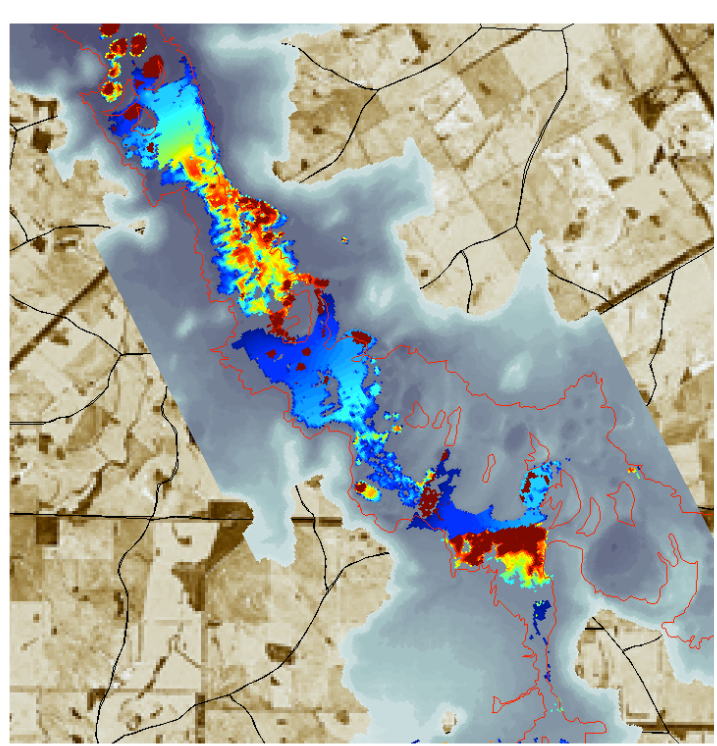

Figure 3. Spatial plot of flood output from the model in the Lake Bryde Nature Reserve at the peak of the Jan 2006 flood event, compared with the digitised flood extent from aerial photographs (red line). Colour scale indicates water depth (m).
The model was configured to include 'levees' to represent raised road formations, floodways, and culverts (these account for pipe diameters and lengths, number of pipes, and head loss on entry). Three levee sets were included to simulate the effects of the Lake Bryde Rd, Pingrup-Newdegate Rd and Mallee Hill Rd raised roadbeds and culverts on the flood propagation. At the bottom of the domain an open boundary was added to drain all water passing through the bottom culvert in order to prevent build up and back flow.

Inflows to the domain from the surrounding LASCAM hillslopes were delivered at a $1 \mathrm{hr}$ time-step, and we therefore created an adapted version of the original code that was based on a daily time-step. Direct rain was also included in the model, both onto the standing water and also to drive the soil hydrological model in the dry cells as they become saturated and contributors. Long term daily rainfall data has been collected from a number of nearby stations. Since 2003 pluviometer (tipping bucket) data has been collected from different locations within the LBNDRC, which specifically cover the Jan 2006 flood event. Daily evaporation was also applied to the simulations and scaled Class-A pan data from the DAFWA Newdegate Research Station was used. 

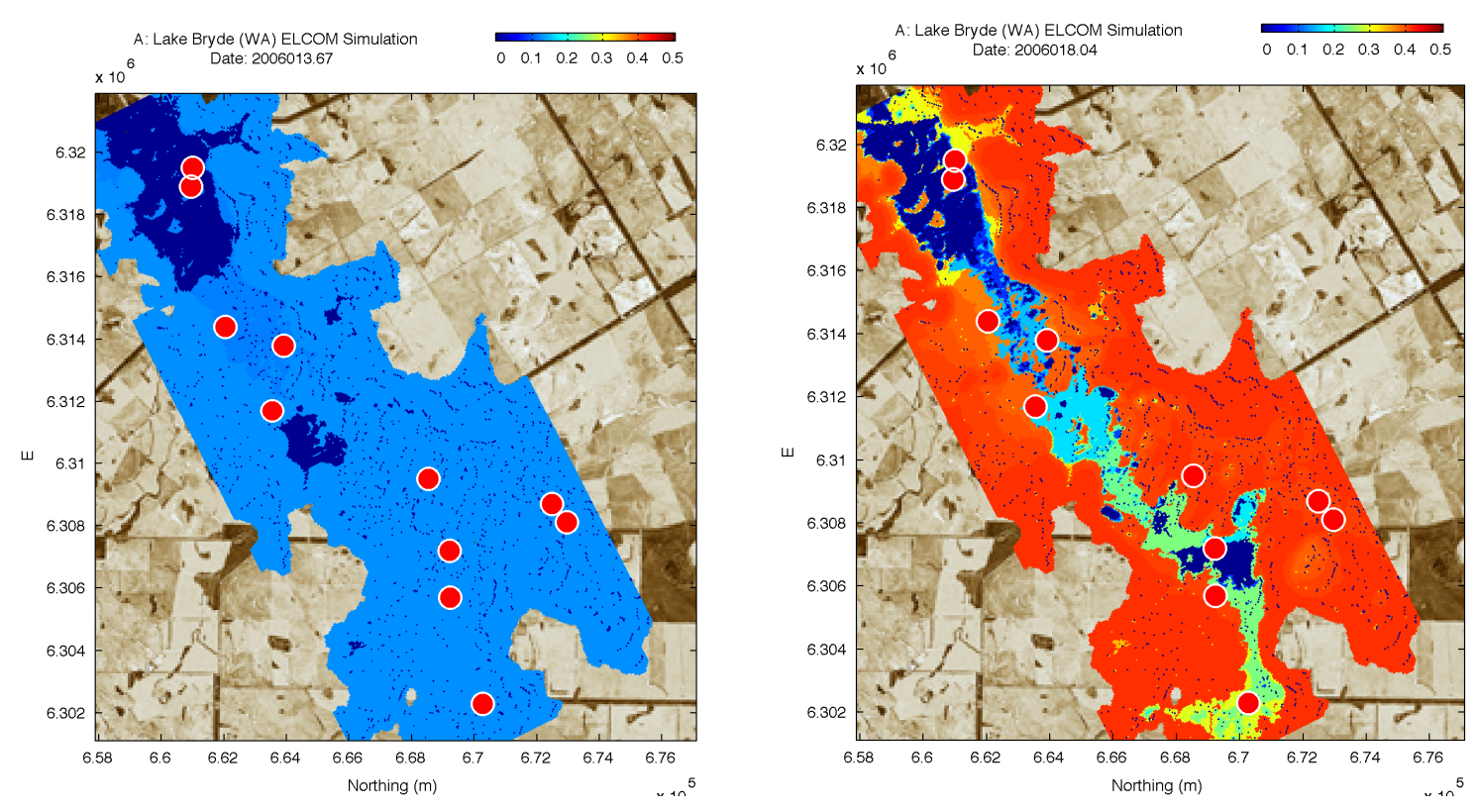

Figure 4. Soil moisture response in Lake Bryde Nature Reserve following the intense Jan 2006 rain on day 13, highlighting areas of inundation (ponding - dark blue), near saturation (waterlogged - light blue \& green) conditions and better drained areas (orange $\&$ red). Colour scale indicates depth of water table below surface $(\mathrm{m})$.

\subsection{Model Results}

Ability to validate the simulations is limited to water level data at critical hydraulic control points, in particular at the road culverts, and water levels inside the main Lake Bryde wetland. As shown in Figure 2 the model performed well in capturing the flood pulse, with the correct peak height, and inflection points on the hydrograph peak show the effect of the spillway (day 13-14), and the subsequent draining through the culvert (day 15-17). Following this, the water in the model remains ponded, although the observed data shows continual drainage, due to inaccuracies in the culvert model at low flows. The water level in Lake Bryde is well captured, with a small offset in depth. The spatial extent of the flood was captured by aerial photography shortly after the rain event. The digitized extent of the flood matches well with the simulated flood extent (Figure 3), though the south-eastern extent is under-predicted. This suggests that the predicted inflow coming from the south-eastern and eastern sub-catchments in the hillslope model has most likely not accounted for the extensive cross-landscape sheet flows that originated from these areas since they are generally not applicable to normal discretised (nodal) sub-catchment generated runoff.

Output of phreatic surface (water table) depths from the soil hydrology module for the nature reserve (Figure 4) highlight areas that have ponded water and how this changes as the flood progresses. It also shows areas that are near saturation, and classified as waterlogged (light blue colouring). The plots also highlight the drainage of the flooded soil following the intense rain on the 13th Jan, which is an important indicator of mediumtong term vegetation susceptibility .

The effect of the engineered waterway on the flood is highly variable along the length of the domain (Figure 5). The model highlights the improved conveyance of flow through the current areas of prolonged flow detention that leads to significant reduction in periods of inundation in high priority management areas where the TEC and high value vegetation assemblages exist.

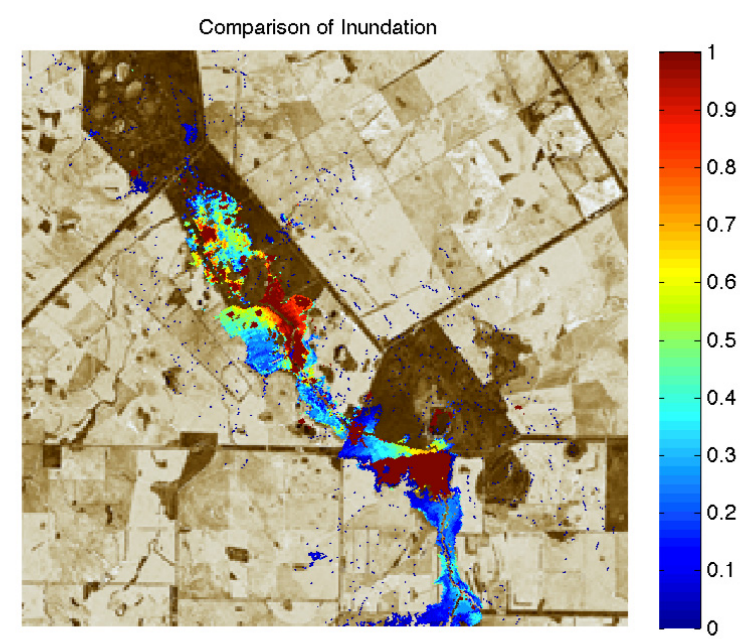

Figure 5. Difference in inundated period (days) between the base and channel scenarios. Dark red areas are less inundated by $>1$ day with the waterway in place. 


\section{LAND-USE MANAGEMENT IN LAKE BRYDE RECOVERY CATCHMENT}

The model has also been applied to explore the wider Lake Bryde catchment hydrological response to rainfall variability and different spatial patterns of vegetation distribution. This provides indicative quantification of how climate and land-use management might impact on downstream water delivery.

\subsection{Model Application}

The catchment model is configured to have spatially variable vegetation properties, with the percentage of remnant vegetation that contributes to each sub-catchment calculated by an intersection of the remnant vegetation shapefile and the model sub-catchments; the resultant fractions showed variable coverage from $10-100 \%$. In the model, a representative Leaf Area Index (LAI, $\mathrm{m}^{2}$ leaf $/ \mathrm{m}^{2}$ ) must be defined for deep-rooted trees (ie. remnant vegetation). Based on review of several papers and reports (Holland, 1969; Hill et al., 2006), an average of 2.6 for typical native woodland cover was chosen, and a seasonality was assumed with this value reduced to 0.7 in Apr and 1.3 in Oct. A range of scenarios were explored including those related to land management activities (related to re-vegetation options) and also the effects of altered climatic regimes:

1. Re-vegetation (1990-2060): The first option is the strategic re-vegetation of farmland with oil mallee rows. This aims to test the effect of strategically implementing rows of oil mallees in cleared farmland to determine their effect on the sub-catchment scale water balance, and also on the amount of water being delivered to the valley floor. Three densities were tested $\left(D_{\text {mallerows }}\right)$, including $10 \%, 20 \%$ and $30 \%$ to determine the sensitivity of flows to increasing numbers of mallee rows (only $20 \%$ reported here). The mallees are prescribed an indicative LAI of 1.5, which is an intermediate estimate from available literature (Holland, 1969), and notably less than the mature remnant vegetation value described previously. It is assmed to have the same seasonal LAI pattern as above. The implementation of oil mallees was set to gradually phase in over a $5 y$ r period from 2015-2020, defined by an implementation function, $I(t)$. For the purposes of parameterizing LASCAM the fraction of each sub-catchment covered by deep-rooted species is defined as:

$F_{\text {deeprooted }}(t)=F_{\text {remnant }}+\left(1-F_{\text {remnant }}\right) \times D_{\text {malleerows }} \times I(t)$

The second option is the adoption of salt-tolerant pastures. To investigate the potential benefit of salt-tolerant pastures on shedding of water and downstream flows, we adjust the infiltration capacity of the 'crop' zone in the hill-slope model. Whilst this is a simplistic representation of the benefit of salt-tolerant pastures, the role in shaping hydrological dynamics is by reducing runoff by promoting infiltration and preventing shedding under mild rain events. The infiltration capacity was increased to $20 \mathrm{~mm}$ to simulate a modest improvement in managing surface water re-infiltration, and to $40 \mathrm{~mm}$ to test the sensitivity of this parameter.

2. Climate Futures (1990-2050): A climate change scenario is compared to a base scenario that uses historical Newdegate Post-Office rainfall data repeated for each decade to 2050, and baseline vegetation properties. The climate change scenario is created from downscaled CSIRO GCM output and assuming the IPCC scenario A2f2, from 2010-2050. This data is down-scaled using a NHMM method developed by Charles et al. (2004) and we adopt the nearby Lake Grace town-site as the down-scaled location.

\subsection{Model Results}

Planting of oil mallees on farmland had a significant impact on water table levels but only a marginal impact on the frequency distribution of surface flows entering the downstream environment. Conversely, promoting enhanced salt-tolerant pastures had less of an impact on water table levels but a considerable impact on the frequency distribution of surface flows (Figure 6). The figures demonstrate sensitivity of flow and water stores to climate and vegetation, so here we combine the effects to determine potential future scenarios of relevance to management. These include a 'do nothing' scenario which assumes no management actions, with a stationary climate; a 'land management' scenario that assumes oil mallee row implementation (at 20\% density) and adoption of salt-tolerant pastures as a standard; and a combined 'land management + climate change' scenario. The results demonstrate the positive potential for land management, both under stationary and future climate scenarios. The simulations highlight the importance of reducing surface runoff in managing excess flow impacts within the downstream valley floor ecosystem. Whilst deep-rooted vegetation is necessary and effective at reducing water tables, managing surface water is necessary for preventing excess flows to downstream landscapes.

We are also interested in understanding the effect of these changes at the catchment level and how they impact valley floor flow regimes, and in particular the valley floor biodiversity. An integrated flow duration curve is used to define changes in patterns of the total flow reaching the downstream landscape and includes all flows reaching the valley floor perimeter from the surrounding farmland (Figure 6c). It highlights that catchment-wide land management has a significant effect on delivery of flows to the valley floor, and notably different from the pattern seen at the hillslope scale (eg. Figure 6a,b). 

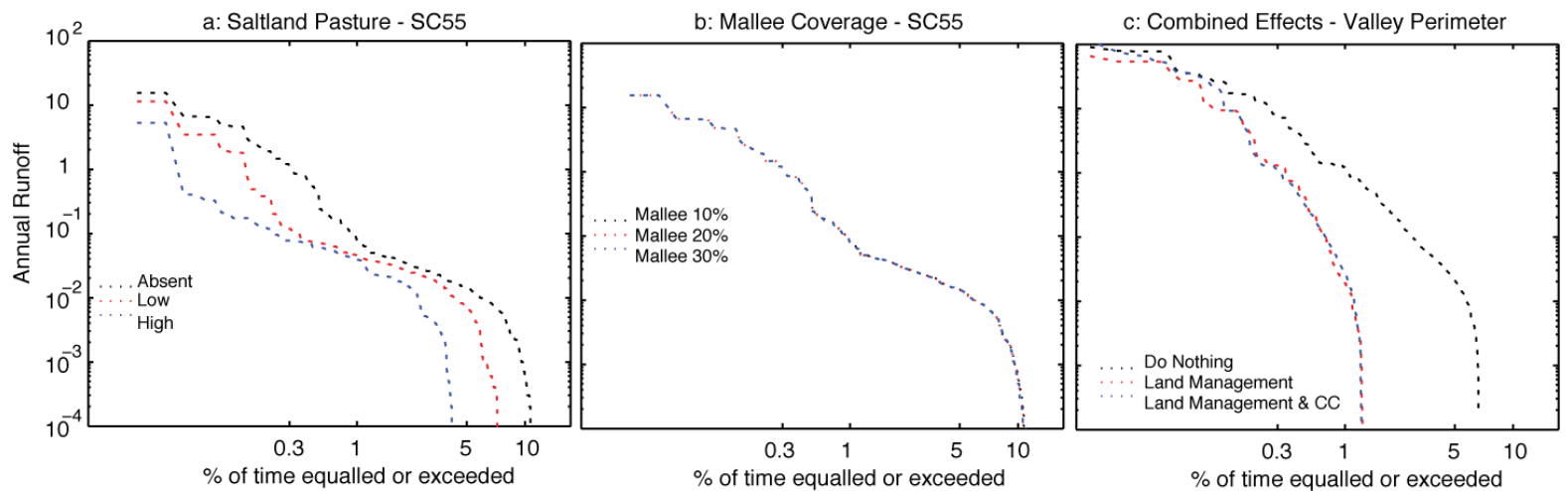

Figure 6. Flow duration curve for the simulated period for a) an upstream sub-catchment showing the effect

of implementing salt-land pastures, b) an upstream sub-catchment showing the effect of implementing oil mallees, and c) comparing 'do nothing' with a combined 'land management' and 'land management + climate change $(\mathrm{CC})$ ' scenario for the total flow entering the valley-floor perimeter.

\section{CONCLUSIONS}

1. The coupled approach provides for a balance of computational efficiency and simplification that may not be possible from the use of one modelling approach.

2. The model boundaries/extent can be changed to suit the scope of interest (ie. larger or smaller areas), with potential to also add actual data or alternate inputs in place of the LASCAM simulated data.

3. The role of the soil zone is very important to assessing remnant and re-vegetation impacts upon hydrological processes. These must be represented but quickly become complex in many models. The approach suggested here is deemed to be sufficient to reach a parsimonious balance.

4. The results suggest that in dry climates the role of local soil wetting and saturation is important in controlling runoff generation and flow continuity thresholds. This was reflected in the effect that adding these had compared to earlier development versions that used more traditional overland hydraulic routing.

5. The approach is a step towards addressing the challenge of model validation in data sparse environments, whereby water depth and extent is usually more readily available than actual flow data.

\section{ACKNOWLEDGMENTS}

We gratefully acknowledge funding support from the Department of Environment and Conservation and Future Farm Industries CRC. Data was provided by Lake Bryde Natural Diversity Catchment project.

\section{REFERENCES}

Charles, S.P., Bates, B.C., Smith, I.N. and Hughes, J.P. (2004). Statistical downscaling of daily precipitation from observed and modelled atmospheric fields. Hydrol. Process., 18(8), 1373-1394.

Costelloe, J.F., Grayson, R.B., Argent, R.M. and McMahon, T.A. (2003). Modelling the flow regime of an arid zone floodplain river, Diamantina River, Australia. Environ. Modell. Softw., 18, 693-703.

Costelloe, J.F., Grayson, R.B., and McMahon, T.A. (2006). Modelling streamflow in a large anastomosing river of the arid zone, Diamantina River, Australia. J. Hydrol., 323, 138-153.

Farmer, D., Sivapalan, M. and Lockley, I (2000). Assessing vegetation influence on water balance in rehabilitation landscapes using simple storage models, Proceedings of the 3rd International Hydrology and Water Resources Symposium (Hydro 2000), Perth, November 2000, Institution of Engineers Australia.

Farmer, D., Sivapalan, M. and Jothityangkoon, C. (2003). Climate, soil, and vegetation controls upon the variability of water balance in temperate and semiarid landscapes: Downward approach to water balance analysis. Water Resour. Res., 39(2): 1035-1056.

Hill, M.J., Senarath, U., Lee, A., Zeppel, M., Nightingale, J.M., Williams, R.J. and McVicar, T.R. (2006). Assessment of the MODIS LAI product for Australian ecosystems. Rem. Sens. Environ., 101(4), $495-518$.

Holland, P.G. (1969). The maintenance of structure and shape in 3 mallee eucalypts, New Phytol, 68,411-421

Sivapalan, M., Viney, N.R., and Zammit, C. (2002). LASCAM: Large Scale Catchment Model. In V.P. Singh \& D.K. Frevert (Eds), Mathematical Models of Large Watershed Hydrology. Highlands Pk, Colorado.

Viney, N.R. and Sivapalan, M. (2000). Modelling catchment processes in the Swan-Avon River Basin. Hydrol. Process., 15(13), 2671-2685. 